\title{
Problem-Based Learning in nursing education at Hue University of Medicine and Pharmacy, Vietnam: Perspective and needs assessment
}

\author{
Thi Anh Phuong Nguyen ${ }^{1}$ Sunjoo Kang ${ }^{2}$. Thi Thuy Trang Ho ${ }^{1} \cdot$ Ba Hai Mai $^{1}$. \\ Thi Diem Binh Vo' ${ }^{1}$ Vu Quoc Huy Nguyen ${ }^{3}$ \\ 1: University Lecturer, Faculty of Nursing, Hue University of Medicine and Pharmacy, Vietnam \\ 2: Assistant Professor, Cheju Halla University, Republic of Korea \\ 3: Professor, Faculty of International Education, Hue University of Medicine and Pharmacy, Vietnam
}

\section{ABSTRACT}

Purpose: The purpose of this study was to examine faculty and student perspectives on and learning needs about Problem-based Learning (PBL) methodology.

Methods: A cross-sectional study using a questionaire. Descriptive statistics were applied to analyse the data from 41 faculty members and 236 nursing students.

Results: The data showed that $66.8 \%$ of students and $17.1 \%$ of faculty had never known about problembased learning. Most faculty and students believed that this method could be applied into nursing education $(97.6 \%$ and $98.6 \%$, respectively). The mean age of faculty members was $29.05(\mathrm{SD}=8.57)$ and students was $20.20(\mathrm{SD}=.67)$.

Data on the use of technology for information searches and updating knowledge essential for evidencebased practice, showed that most faculty used Laptops (26.8\%) and Smartphones (19.5\%) while nursing students $(31.4 \%)$, mostly used Smartphone only. The average internet use time daily was 3 to 6 hours for faculty $(43.9 \%)$, and students $(40.3 \%)$.

Faculty members and students perceived that the benefits of the methodology were that "students were more active and self-directed in learning", it provided a means for "systematic problem solving", and had the potential for "enhancing critical thinking skills", "deeper understanding of problems" and "improvement in individual skills". The disadvantages were that "faculty spent more time on the course", "faculty required both theory and clinical knowledge/experience". The student perspective was focused on PBL as "a new method" and that "students were required to have more comprehensive knowledge".

Conclusion: Understanding the perspective of nursing students about the methodology of PBL will help faculty better understand the student's learning needs. This is of prime concern for student centred learning and necessary information for nursing faculty in order to design and continually develop an appropriate nursing curriculum for contemporary practice in the future.

Keywords: Problem-Based Learning, Nursing education, Learner perspectives, Learner needs 


\section{INTRODUCTION}

Problem based learning (PBL) is a learning and teaching philosophy and methodology;; it is used in many medical, health and other professions' schools worldwide. Evidence suggests several positive effects of PBL: enhanced, deeper knowledge acquisition, improved collaborative skills, better engagement and motivation, and the potential for enhanced critical thinking and problem-solving skills among students (Mergendoller, et al., 2006; Wood 2003;). According to Levin (2001), the researcher described PBL is a tool that can promote more active learning experiences. Chung \& Chow (2004) found that PBL promotes the ability to apply appropriate meta-cognitive and reasoning strategies.

In the 21st century, nursing competencies require nurses with more knowledge, more evidence-based education, and more relevant skills (Bartels, 2005). Shin, Lee, Ha, and Kim (2006) revealed that there was an urgent need for nursing education to develop an appropriate teaching strategy to enhance nursing students' critical thinking. Beers and Bowdeen (2005) showed that nursing students had improvement in long-term knowledge retention with PBL. Therefore, proposals for more innovative teaching and learning strategies in nursing education have been part of ongoing development since the 1970s; the aim is to engage students to assume an active role in their education.

In Vietnam, traditional teaching and learning strategies were more commonplace in health professional education. Based on networks of global interactions and collaborations, more active teaching and learning approaches have spread into health education systems. However, Tran and his colleagues (2014) revealed that perceptions of students and instructor s revealed difficulties as each novel educational skill was presented for consideration as an alternative. However in 2014, the utilization of PBL approach had started in Hue University of Medicine and Pharmacy through the support of capacity building project, the Vietnamese Nursing Program along with the establishment of an Emergency Medicine Education Center project. Simulation-Problembased learning (SPBL) methods and an e-learning system was introduced in workshops on "Developing on practiced based nursing curriculum". Therefore, the purpose of this study was to evaluate students' perspective and learning needs about PBL methodologies.

\section{METHOD}

Two-hundreds and thirty-six nursing students from second to fourth year, and 41 faculty members from the Faculty of Nursing, Hue University of Medicine and Pharmacy, Vietnam participated in a cross-sectional survey; A questionnaire was developed and validated by using a standardized procedure which included item development and pilot-testing. Three experts appraised the content validity of the questionnaire; Cronbach's alpha coefficients were 0.96 and 0.95 , indicating adequate test and re-test reliability and internal consistency for each domain. Descriptive statistics were applied to analyse the data. A content analysis technique was employed to analyze descriptive qualitative data. Statistical analysis was performed using the Statistical Package for Social Sciences (SPSS) software.

Ethics approval for this study was obtained from the Ethical Committee for Human Research at Hue UPM and written informed consent was obtained from all participants. 


\section{RESULTS}

The results of this study indicated that the mean age of faculty was 29.05 ( $\mathrm{SD}=8.57$ ) and of student was 20.20 (SD $=.67$ ). The length of experience of faculty was 5.07 years, with the longest working time 20 years, and the shortest 1 year. On issues about using technology for searching information and updating knowledge, the study showed that most faculty members used Laptop and Smartphone accounted for $26.8 \%$, and $19.5 \%$ of faculty used Desktop and/or Laptop computers, Smartphones, and Tablets. While nursing student mostly used Smartphones (31.4\%), followed by Laptops (23.7 \%), there was still $13.6 \%$ of student has not had an opportunity to use those technologies for learning (Table 1).

The average amount of internet usage, time per day, was 3 to 6 hours for faculty members (43.9\%), and students (40.3\%), and less than 3 hours for faculty (31.7\%), and for

TABLE 1: Facilities for searching information and updating knowledge

\begin{tabular}{|c|c|c|c|c|}
\hline \multirow{2}{*}{ Facilities } & \multicolumn{2}{|c|}{ Student } & \multicolumn{2}{|c|}{ Faculty } \\
\hline & $\mathrm{N}$ & $\%$ & $\mathrm{~N}$ & $\%$ \\
\hline Desktop computer & 14 & 5.9 & 2 & 4.9 \\
\hline Laptop computer & 56 & 23.7 & 8 & 19.5 \\
\hline Tablet & 3 & 1.3 & 2 & 4.9 \\
\hline Smartphone & 74 & 31.4 & & \\
\hline Laptop and Smartphone & 41 & 17.4 & 11 & 26.8 \\
\hline $\begin{array}{l}\text { Desktop and Tablet and } \\
\text { Smartphone }\end{array}$ & 3 & 1.3 & 3 & 7.3 \\
\hline $\begin{array}{l}\text { Desktop and Laptop and } \\
\text { Smartphone }\end{array}$ & 4 & 1.7 & 6 & 14.6 \\
\hline Desktop and Smartphone & 6 & 2.5 & & \\
\hline Tablet and Smartphone & 3 & 1.3 & & \\
\hline Desktop and Laptop & & & 1 & 2.4 \\
\hline All & & & 8 & 19.5 \\
\hline Nothing & 32 & 13.6 & & \\
\hline Total & 236 & 100.0 & 41 & 100.0 \\
\hline
\end{tabular}

TABLE 2: Internet usage: Amounts of time per day

\begin{tabular}{lcccc}
\hline \multirow{2}{*}{$\begin{array}{l}\text { Time of internet } \\
\text { use/ day }\end{array}$} & \multicolumn{2}{c}{ faculty } & \multicolumn{2}{c}{ Student } \\
\cline { 2 - 5 } & $\mathrm{N}$ & $\%$ & $\mathrm{~N}$ & $\%$ \\
\hline$<3 \mathrm{~h}$ & 13 & 31.7 & 134 & 56.8 \\
\hline $3-6 \mathrm{~h}$ & 18 & 43.9 & 95 & 40.3 \\
\hline 6h & 10 & 24.4 & 7 & 3 \\
\hline Total & 41 & 100.0 & 236 & 100.0 \\
\hline
\end{tabular}

students (56.8\%) (See Table 2)

On findings fromthis study, the results showed that 97.6 $\%$ of faculty members and $80.1 \%$ of students recognized the appropriate role of faculty and students in nursing education was greater focus on student-centered learning. In addition, $66.8 \%$ of students and $17.1 \%$ of faculty members did not know about PBL methodology. Among participants who knew about this method, $46.8 \%$ of students had heard from faculty, $43.0 \%$ of students from e-books. Moreover, $97.6 \%$ of faculty members and $98.6 \%$ of students believed that this method could be applied into nursing education. They thought that it was necessary to apply PBL methods in nursing education (faculty $58.5 \%$, students $72.4 \%$ ).

The data also showed that $53.7 \%$ of faculty and $62.8 \%$ of students suggested application of PBL methods into nurse education by beginning with one or two subjects then expanding to others.

TABLE 3: Faculty and student opinions on the need for application of PBL

\begin{tabular}{lrrrr}
\hline \multirow{2}{*}{ Level of necessity } & \multicolumn{2}{c}{ Student } & \multicolumn{2}{c}{ Faculty } \\
\cline { 2 - 5 } & $\mathrm{N}$ & $\%$ & $\mathrm{~N}$ & $\%$ \\
\hline Very necessary & 33 & 14.9 & 13 & 31.7 \\
\hline Necessary & 160 & 72.4 & 24 & 58.5 \\
\hline Less necessary & 9 & 4.1 & 1 & 2.4 \\
\hline No necessary & 1 & 0.5 & & \\
\hline No comment & 18 & 8.1 & 3 & 7.3 \\
\hline Total & 221 & 100.0 & 41 & 100.0 \\
\hline
\end{tabular}


Another aspect of this study drew on qualitative data on participants' perceptions of PBL benefits and challenges. When faculty members were asked about their understanding of PBL, they suggested that it was "student study based on real situations or nursing problems" and "student centered learning" and "the faculty member is the facilitator". Faculty and student perceived that the benefits of PBL were that "students were more active and self directed in learning", that it enabled "systematic problem solving", and the potential for "enhancing critical thinking skills" and "deeper understanding of problems", "improvement in individual skills". The disadvantages were the need for "faculty to spend more time on the course" and that "faculty required both theory and clinical knowledge and experience", "student perceptions of PBL as a new method" and that "students required more comprehensive knowledge".

\section{DISCUSSION}

Transferring from traditional approaches of teaching to a student-centered PBL approach has been promoted worldwide but in this instance, like elsewhere, has been challenging to both faculty members and students. Nevertheless, it is interesting to note the strategies that they brought in. For example, the average internet usage per day in this study was 3 to 6 hours for faculty (43.9\%), and student (40.3\%). This is consistent with the study conducted by Chan and his colleagues (2015). They investigated facilitators' and students' perceptions of mobile device usage in PBL tutorials. The results reported that all students brought their mobile devices (mostly laptops/ notebooks, smart phones, and tablets) to PBL tutorials. According to the Internet Center of Vietnam (2012), Vietnam joined the global internet network on November 19, 1997 and has about 31.1 millions of internet users $(35,49 \%$ of total population), mainly from $15-24$ years old. Internet has become the second common means for access information just after television. Interestingly, Chan et al. (2015) revealed that it took a lot of time and effort for students to critically assess the information generated from online searches and select the relevant information that might contribute to classroom discussion. This relates to the need for acknowledgement of greater student autonomy and self-direction in learning and indicates that internet using time is an important parameter to the successful development of adult learning skills today.

In this study, $97.6 \%$ of faculty members and $80.1 \%$ of students recognized that student-centred learning was central to contemporary nurse education; students must be at the centre of learning as active learners and more independent thinkers. The concept of studentcentered learning focuses on critical thinking, active learning and real-world assignment (Wohlfarth, 2008). The active learning was applied at HueUMP since 1998. Then it was introduced to nursing program in 2002. A study conducted by Tiwari, Lai, So, and Yuen (2006) demonstrates the benefits of student-centred learning using PBL methodology. They randomly assigned students to both a lecture-based and a PBL nursing therapeutics course over one academic year and examined self-perceptions of participants' critical thinking skills. Critical thinking was measured by means of an inventory administered four times (prior to the first semester, at the end of second semester, and follow-ups after one and two years). The groups did not differ on self-reported critical thinking prior to the semester, but PBL students showed significantly greater improvement in critical thinking over time. In another study, Arpanantikul and Luecha (2010) explored perceptions of undergraduate Thai nursing students regarding problem-based learning. Positive perceptions found include: being an active learner; being a systematic learner; developing friendly relationships; 
adjusting personal characteristics when learning; and, having freedom while learning. These are consistent with the findings from this study. It is warranted to measure these perceived benefits with reliable and valid tools over time in future research.

Despite of the benefits and preference for PBL, some perceived disadvantages were reported in this study such as "faculty spend more time on course", "faculty require both theory and clinical knowledge and experience", "student perceptive as a new method", "students require comprehensive knowledge". Other limitations of PBL are reported in literature. Arpanantikul and Luecha (2010) found negative perceptions which included; being unexcited about learning, carrying out time-consuming learning activities, and obtaining limited knowledge. Seneviratne and colleagues (2001) also reported that time-consuming was the main disadvantage perceived in students' awareness about PBL. Maudsley and colleagues (2008) reported that students found the lack of an overt syllabus to be a disadvantage of PBL because they experienced feelings of uncertainty about whether they had studied the appropriate literature. However, Nel and colleagues (2008) suggested that students' uncertainty due to the application of PBL methodology can be overcome by students' assuming personal responsibility for learning and greater and self-directedness. These are important features of learning outcomes for the health professions where clinical judgment for sound decision-making is imperative.

\section{CONCLUSION}

This study aimed to identify faculty's and student's perspectives on PBL and learning needs around the adoption of the methodology. This is necessary information for nursing faculty in order to professionally and personally develop their roles in the design of appropriate nursing curriculum for evidence-based practice for the future. It is critical that nurse educators understand student's learning needs and their perspective on how best to learn in a manner that accommodates personal styles of learning. Increasing access to technology will enhance the likelihood of faculty and student access to evidence about the best practices for optimal patient outcomes.

\section{REFERENCES}

Arpanantikul, M., \& Luecha, Y. (2010). Problem-Based Learning: Undergraduate Thai Nursing Students' Perceptions. Pacific Rim Int J Nurs Res, 14(3), 262-276.

Bartels, J.E. (2005). Educating nurses for the 21st century. Nursing and Health Science, 7(4): 221-5.

Beers, G. W. Bowden, S. The effect of teaching method on long-term knowledge retention. Journal of Nursing Education, 44, 511-514.

Chan, L. , Bridges, S. M. , Doherty, I. , Ng, M. , Jin, J. , Sharma, N. , Chan, N. , \& Lai, H. Y. (2015). A Qualitative Study on How Health Professional Students and Their PBL Facilitators Perceive the Use of Mobile Devices During PBL. Interdisciplinary Journal of Problem Based Learning, 9 (1). Available at: http://dx.doi.org/10.7771/1541-5015.1510

Chung, J.C.C. \& Chow, S.M.K. (2004). Promoting student learning through a student-centered problem-based learning subject curriculum. Innovation in Education \& Teaching International, 41(2), 157-1 68

Maudsley, G., Williams, E. M. I., \& Taylor, D. C. M. (2008). Problem-based learning at the receiving end: A 'mixed methods' study of junior medical students' perspectives. Advances in Health Sciences Education, 13, 435-451.

Mergendoller, J. R., Maxwell, N. L., \& Bellisimo, Y. (2006). The effectiveness of problem-based instruction: Acomparative study of instructional methods and student characteristics. The Interdisciplinary Journal of Problem-based Learing, 1(2), 49-69. 
Nel, P. W., Keville, S., Ford, D., McCarney, R., Jeffrey, S., Adams, S., \& Uprichard, S. (2008). Close encounters of the uncertain kind: Reflections on doing problembased learning (PBL) for the first time. Reflective Practice, 9, 197-206.

Seneviratne R.D, Samarasekera D.D; Karunathilake M; Ponnamperuma G.G (2001) Students' perception of problem-based learning in the medical curriculum of the Faculty of Medicine, University of Colombo. Ann Acad Med Singapore, 30(4):379-81.

Shin, K. R., Lee, J., Ha, J. Y., \& Kim, K. H. (2006). Critical thinking dispositions in baccalaureate nursing students. Journal Advanced Nursing, 56(2), 182-9.

Tiwari, A., Lai, P., So, M., \& Yuen, K. (2006). Comparison of the effects of problem based learning and lecturing on the development of students' critical thinking. Medical Education, 40, 547-554.

Tran, M. T., \& Do, M. H. (2013). Status of internet using and its impact on students at Agricultural University of Ho Chi Minh. Available at www2.hcmuaf.edu.vn/ data/tmtri/.../Internet\%20use\%20of\%20students.pdf

Tran, T. Q., Scherpbier, A., van Dalen. J., van Do D., \& Wright, E. P. (2014). Implementing a skillslab training program in a developing country. Educ Health,27, 243-8

Wohlfarth, D., Sheras, D., Bennett, J. L., Simon, B., Pimentel, J. H., \& Gabel, L. E. (2008). Student perceptions of learner-centered teaching. InSight: $A$ Journal of Scholarly Teaching, 3, 67-74.

Wood, D. F. (2003). Problem based learning. BMJ, 326, 328-30 